\title{
Effect of Alginate Additives on the Microstructure and Properties of Phytic Acid-based Conversion Coating on a Steel Surface
}

\author{
Yong $\mathrm{Lu}^{1,2, *}$, Huixia Feng ${ }^{1}$ \\ ${ }^{1}$ School of Petrochemical Engineering,Lanzhou University of Technology,Lanzhou,Gansu China \\ ${ }^{2}$ Research Institute of Lanzhou Petrochemical Corporation of Petrochina,Lanzhou,Gansu China \\ *E-mail: luyong19850627@163.com
}

doi: $10.20964 / 2019.12 .04$

Received: 24 May 2019/ Accepted: 22 July 2019 / Published: 29 October 2019

Phytic acid (PA) has a potential use as a coating on metal surface to retard corrosion. However, a loose structure and micro-cracks in the phytic acid coating layer damage the tightness of the coating, providing channels for the infiltration of corrosive media and seriously weakening the protective effect of the coating. Sodium alginate (SA) was added as an accelerating agent to improve the anti-corrosion protective effect and coating densification of the phytic acid coating on a Q235 steel surface. The micro-morphology, elemental composition and elemental chemical state of different samples were observed by the surface analysis technologies of scanning electron microscopy (SEM) equipped with X-ray energy dispersive spectrum (EDS) and X-ray photoelectron spectroscopy (XPS), all of which show a dense and homogenous phytic acid film with lower crack was precipitated on the sample treated by PA-SA conversion coating. Atomic force microscopy (AFM) and contact angle measurements were used to evaluate the adhesion properties of the prepared coating and the results showed that the PA-SA coated steel exhibited better wettability and adhesion to the top layers compared to the bare steel and phytic acid coating. The electrochemical measurements show that the corrosion resistance of the conversion coating was markedly improved on the steel substrate treated by phytic acid conversion bath containing SA.

Keywords: sodium alginate; conversion coating; phytic acid adhesion; corrosion

\section{$\underline{\text { FULL TEXT }}$}

(C) 2019 The Authors. Published by ESG (www.electrochemsci.org). This article is an open access article distributed under the terms and conditions of the Creative Commons Attribution license (http://creativecommons.org/licenses/by/4.0/). 